\title{
O TREINO DA FLEXIBILIDADE MUSCULAR E O AUMENTO DA AMPLITUDE DE MOVIMENTO: UMA REVISÃO CRÍTICA DA LITERATURA
}

\author{
THE MUSCULAR FLEXIBILITY TRAINING AND THE RANGE \\ OF MOVEMENT IMPROVEMENT: A CRITICAL LITERATURE REVIEW
}

\begin{abstract}
AUTORES
Luís Filipe dos Santos Coelho'

${ }^{1}$ Fisioterapeuta e Professor de Pilates do Consultório e Clínica de Reabilitação, Lda. - Lisboa

O TREINO DA FLEXIBILIDADE MUSCULAR E O AUMENTO DA AMPLITUDE DE MOVIMENTO: UMA REVISÃO CRÍTICA DA LITERATURA 4(3): $61-72$
\end{abstract}

\section{PALAVRAS-CHAVE}

estiramento passivo; estiramento activo; facilitação neuromuscular proprioceptiva; aquecimento; coeficiente de elasticidade.

\section{KEYWORDS}

passive stretching; active stretching; proprioceptive neuromuscular facilitation; warming; elasticity coefficient.

data de submissão

Julho 2006

data de aceitação

Maio 2007

\section{RESUMO}

0 treino da flexibilidade muscular põe em evidência uma série de princípios neurofisiológicos e um conjunto intrincado de propriedades musculares e visco-elásticas. São diversos os métodos de estiramento realizados nos contextos clínico e desportivo. Apesar da sua utilização ser comum, não é usual os profissionais de saúde e educação reflectirem sobre as componentes e eficácia dos diversos métodos de estiramento. Neste artigo, realizamos uma revisão crítica dos diversos métodos utilizados no treino de flexibilidade, assim como dos princípios e parâmetros que com eles se relacionam. Daremos especial ênfase aos princípios em que se baseia a facilitação neuromuscular proprioceptiva e os diversos métodos de relaxamento local, como o aquecimento. Para além disso, teremos em conta os dados reveladores relativos ao paradoxo do Coeficiente de elasticidade, os quais podem ajudar a conceber uma filosofia de intervenção do treino de flexibilidade divergente relativamente ao que classicamente tem sido defendido e efectivado.
ABSTRACT

The muscular flexibility training put in evidence a train of neurophysiological principals and an intricate amount of muscular and viscous-elastic properties. There are a lot of stretching methods, used on the clinical and sport contexts. Despite its common utilization, it isn't usual the health and educational professionals reflect about the compounds and efficacy of the diverse stretching methods. In this article, we realize a critical review about the diverse methods used on the flexibility training, as the principles and parameters related with that. We will done special emphasis to the principles of the proprioceptive neuromuscular facilitation and the diverse local relaxation methods, like warming. We will also have in count the revealing data relating to the Elasticity Coefficient paradox, witch can help to conceive an intervention philosophy of the flexibility training different from what it have being defended and practiced. 


\section{INTRODUCÃO}

Conceptualmente, a flexibilidade muscular tem sido definida em termos da amplitude de movimento disponível por parte de uma articulação, amplitude essa dependente da extensibilidade dos músculos. Podemos atender à flexibilidade como "a habilidade para mover uma articulação ou articulações através de uma amplitude de movimento livre de dor e sem restrições, dependente da extensibilidade dos músculos, que permite que estes cruzem uma articulação para relaxar, alongar e conter uma força de alongamento" ${ }^{1}$, p. 142, cap. 5). 0 treino de flexibilidade é utilizado cada vez mais frequentemente nos contextos clínico e desportivo, tanto na preparação como na conclusão de treinos, assim como parte de treinos autónomos que visam o estiramento global ou a reeducação postural.

Neste artigo, iremos rever os diferentes tipos de métodos terapêuticos utilizados para alongar os tecidos moles, considerando uma revisão sustentada da literatura, tanto no respeitante às diferentes modalidades e variantes de alongamento, como no respeitante aos diferentes parâmetros de estiramento muscular, como a frequência e a duração dos estiramentos. Iremos igualmente questionar a eficácia de uma série de modalidades de intervenção com vista ao ganho de flexibilidade, tendo sempre em conta a literatura existente.

\section{DESENVOLVIMENTO}

Propriedades mecânicas e neurofisiológicas dos tecidos

A flexibilidade está dependente de diversas propriedades mecânicas e neurofisiológicas do tecido contráctil e do tecido não contráctil.
As propriedades neurofisiológicas do tecido contráctil estão dependentes do funcionamento do fuso neuromuscular, do órgão tendinoso de Golgi e das fibras neuronais associadas, estruturas envolvidas num complexo processo de inervação recíproca.

As propriedades mecânicas do tecido muscular dependem dos sarcómeros e respectivas pontes transversas de actina e miosina. Quando um músculo é alongado passivamente, 0 alongamento inicial ocorre no componente elástico em série e a tensão aumenta agudamente. Após certo ponto, ocorre um comprometimento mecânico das pontes transversas à medida que os filamentos se separam com o deslizamento e ocorre um alongamento brusco nos sarcómeros ${ }^{2}$. Se um músculo é imobilizado na posição alongada por um período prolongado de tempo, o número de sarcómeros em série aumenta, dando origem a uma forma mais permanente de alongamento muscular. 0 músculo irá ajustar o seu comprimento com o tempo de modo a manter a maior sobreposição funcional entre actina e miosina ${ }^{3}$.

As características mecânicas do tecido mole não contráctil estão dependentes das forças de sobrecarga e distensão tecidular, sendo que a curva sobrecarga - distensão concebe o comportamento dos tecidos perante uma força de deformação. Quando sobrecarregadas, inicialmente as fibras de colagéneo alongam-se. Com sobrecarga adicional, ocorre deformação recuperável na amplitude elástica. Assim que o limite elástico é alcançado, ocorre falha sequencial das fibras de colagéneo e no tecido na amplitude plástica, resultando em libertação de calor e um novo comprimento quando a sobrecarga é libertada, ${ }^{4,5}$.
O comportamento visco-elástico dos tecidos moles durante um alongamento compõe-se de uma deformação ou creep, expressando-se mais precisamente na fluage muscular. Tal comportamento muscular pode ser expresso pela seguinte equação ${ }^{6}$ :

Índice de deformação = Força aplicada / Coeficiente de elasticidade $x$ Tempo

A deformação muscular será maior em músculos com menor Coeficiente de elasticidade e estará proporcionalmente dependente da Força aplicada e do factor Tempo. Mais tarde, no decorrer deste artigo, iremos ter em consideração aquilo que pode ser denominado de "paradoxo do coeficiente de elasticidade".

\section{Métodos de estiramento}

Existem três métodos básicos para alongar os componentes contrácteis e não contrácteis da unidade músculo-tendinosa: estiramento passivo, inibição activa (inclui o estiramento activo) e auto-alongamento ${ }^{1}$. 0 auto-alongamento pode envolver alongamento passivo, inibição activa ou ambos.

De seguida, iremos precisar os diversos tipos de alongamento passivo.

\section{Estiramento passivo}

\section{Estiramento passivo manual}

Este é o tipo de estiramento em que o terapeuta ou instrutor aplica uma força externa ao segmento de modo a alongar os tecidos, sem realização de qualquer tipo de esforço por parte do doente ou desportista.

Exploremos seguidamente determinados parâmetros relativos à efectuação deste tipo de estiramentos. Diversos estudos têm sido realizados com vista à compreensão do 
tempo necessário de estiramento com vista à obtenção de uma deformação permanente dos tecidos, ou seja, ao ganho de flexibilidade.

A primeira referência data de $1987^{7}$, estudo no qual o alongamento passivo foi aplicado nos abdutores da anca de indivíduos saudáveis por 15 e 45 segundos e dois minutos, na mesma intensidade. Segundo o estudo, o alongamento de dois minutos não apresentou mais vantagens no aumento da amplitude de movimento que os alongamentos mais prolongados. No estudo de Bandy e Irion ${ }^{8}$, datado de 1994, foi concluído que um estiramento estático de 30 segundos é mais efectivo que os alongamentos de tempos inferiores, mas não mais capaz de produzir melhorias na amplitude de movimento que o estiramento de 60 segundos. Bandy et al. ${ }^{9}$ concluíram também que não há vantagens adicionais na realização de estiramentos com tempos superiores a 30 segundos de duração. Para além disso, demonstraram que não é vantajosa a passagem da frequência de estiramento de uma para três vezes por dia.

À semelhança dos estudos anteriores, Roberts e Wilson ${ }^{10}$ também estudaram os tempos de estiramento estático e passivo em jovens desportistas. Concluíram que estiramentos de 15 segundos eram mais vantajosos que estiramentos de tempos inferiores.

A única investigação com vista ao estudo de tempos de alongamento realizada em indivíduos idosos corresponde ao estudo de Feland et al $^{11}$. Neste estudo, foi demonstrado haver vantagens na realização de estiramentos longos, até 60 segundos de duração. Os autores explicaram os resultados com a necessidade de sujeitos mais idosos, com menor elasticidade tecidular, neces-sitarem de períodos mais prolon-gados de tempo para conseguirem a máxima deformação das suas estruturas musculares.

Um estudo recente 12 apontou para os mesmos resultados, em termos de ganhos de amplitude de movimento, tanto com um estiramento de 30 segundos de duração como com diversos estiramentos de cinco segundos de duração.

Há uma necessidade premente de estudar mais profundamente os tempos necessários à realização de estiramentos, principalmente no respeitante àqueles que são progressivos e globais. Por exemplo, o trabalho de fisioterapia de cadeias musculares, previsto no método de Mézières $^{13}$, Reeducação Postural Global e Stretching Global Activo ${ }^{14}$ e método de Busquet ${ }^{15}$, advoga a realização de estiramentos muito prolongados no tempo. $\mathbf{0}$ trabalho de alongamento realizado nestes métodos respeita escrupulosamente a fórmula da fluage muscular, apresentada no capítulo anterior. Segundo o que a fórmula prediz, Souchard ${ }^{16}$ defende as duas seguintes premissas relativas ao trabalho passivo de alongamento:

1) Quanto mais prolongamos o tempo de alongamento, mais significativo é o comprimento ganho. Para ser eficaz, é preciso, então, praticar posturas de alongamento prolongadas no tempo, não alongamentos bruscos.

2) Quanto mais aumentamos o tempo de alongamento, mais podemos diminuir a força de tracção. A lentidão dos alongamentos, associada à moderação das tracções permite todas as descompressões articulares; só tracções manuais suaves e prolongadas é que permitem o tensionamento progressivamente global das cadeias musculares.
Em última análise, tanto a intensidade quanto a duração do alongamento dependem da tolerância do paciente ou desportista e da resistência física do terapeuta ou instrutor. Um alongamento manual de baixa intensidade aplicado pelo maior tempo possível será mais confortável e mais prontamente tolerado pelo indivíduo, resultando igualmente em mais resultados com maior controlo e segurança do processo de treino ${ }^{17}$.

\section{Estiramento estático vs. Estiramento balístico}

Como vimos, um alongamento mantido por um período mínimo de tempo significa um conjunto amplo de resultados no respeitante ao ganho de amplitude articular. A dependência do factor tempo diz respeito não só à variável temporal prevista na fórmula de fluage muscular, como também a factores de natureza neuromotora. Referimo-nos à acção do reflexo miotático de encurtamento, ligado à sensibilidade do fuso neuromuscular. É bem sabido que um estiramento deve ser suficientemente lento e prolongado de modo a se conseguir vencer a tendência que o músculo apresenta para encurtar no momento do alongamento por acção do reflexo miotático'.

Por essa razão de natureza teorética, actualmente é rara a investigação realizada em torno dos estiramentos ditos balísticos. Estes são alongamentos "bruscos", de alta intensidade, realizados a grande velocidade. Como tal, são estiramentos menos seguros e, provavelmente, menos eficazes em termos do aumento de amplitude de movimento. A tensão ocasionada no músculo derivada da grande velocidade de estiramento e, como tal, da estimulação do reflexo 
miotático, compreende cerca do dobro da tensão ocasionada com o estiramento estático ${ }^{18}$. Na literatura, pode ser encontrado um estudo de $1993^{19}$, segundo o qual o alongamento balístico é menos eficaz do que o alongamento estático na melhoria da elasticidade muscular. Para além disso, o estiramento balístico tem demonstrado não possuir mais vantagens na preparação para o treino de força explosiva relativamente ao estiramento estático ${ }^{20,21}$.

\section{Estiramento passivo mecânico prolongado}

Corresponde ao tipo de alongamento mantido por períodos prolongados de tempo, conseguido por meio da aplicação de uma força externa de baixa intensidade, usando-se o peso do próprio paciente ou sistemas mecânicos como tracção, pesos, sistema de polias, splints dinâmicos ou gessos.

É o tipo de estiramento utilizado em muitas situações de patologia contraturante ou em situações de patologia neurológica com presença de hipertonia e consequente encurtamento e/ou mesmo deformidade segmentar ortopédica.

0 parâmetro tempo de alongamento é concebido como um dos mais importantes a ter em conta neste tipo de estiramentos.

Vários estudos têm sugerido que um período de 20 minutos ou mais é necessário para que o alongamento resulte numa melhoria da amplitude articular quando se utiliza um alongamento mecânico prolongado de baixa intensidade ${ }^{22,23,24}$. Bohannon $^{22}$ avaliou a efectividade de um alongamento de oito minutos dos ísquiotibiais em comparação com 20 minutos ou mais usando um sistema de polias. $\mathbf{O}$ alongamento de oito minutos levou somente a um pequeno aumento na flexibilidade dos ísquiotibiais, que foi perdida num espaço de 24 horas. Sugeriu-se que um alongamento de 20 minutos ou mais seria necessário para aumentar efectivamente a amplitude de movimento numa base mais permanente. Foram igualmente relatados aumentos significativos na amplitude de movimento de indivíduos saudáveis que tinham retracções em membros inferiores, usando-se somente 10 minutos de alongamento mecânico prolongado de baixa intensidade ${ }^{25}$.

Bohannon e Larkin ${ }^{26}$ usaram igualmente um regime de prancha ortostática com calco, posicionando os doentes em pé durante $\mathbf{3 0}$ minutos diários, tendo conseguido aumentar a amplitude dos flexores dorsais do tornozelo em pacientes com problemas neurológicos.

0 alongamento prolongado de baixa intensidade e um aumento na amplitude podem também ser conseguidos mediante a utilização de um splint dinâmico, utilizado durante oito a 10 horas $^{27}$.

A utilização de gessos tem sido relatada sobretudo nos casos de distúrbios neurológicos do primeiro neurónio.

A imobilização gessada é frequentemente utilizada em crianças com paralisia cerebral, principalmente numa fase do tratamento que procede a administração de toxina botulínica ${ }^{28}$ ou outros fármacos.

Booth, Doyle e Montgomery ${ }^{29}$ estudaram a utilização de imobilização gessada curta (abaixo do joelho) em adultos com lesão cerebral (AVC), com o intuito de reduzirem a deformação em equino da tíbio-társica (gerada pelo padrão espástico de flexão plantar). Os autores verificaram que todos os utentes apresentaram relevantes melhorias da amplitude de flexão dorsal da tíbio-társica e uma diminuição da espasticidade dos flexores plantares. Cusick $^{30}$ realizou um estudo de caso único numa criança com diplegia espástica, tendo obtido uma melhoria no comprimento muscular dos ísquiotibiais, após 45 dias de utilização de gessos longos. Antes do tratamento, a criança apresentava um flexum de ambos os joelhos de 40․ Após a utilização de imobilização gessada, intervalada por ajustamentos na amplitude de colocação da tala gessada, a criança já era capaz de realizar a completa extensão do joelho direito (tendo-se mantido um flexum residual de 5 o do joelho esquerdo].

Ada e Canning ${ }^{31}$ referem melhorias na amplitude de flexão dorsal da tíbio-társica noutros estudos em crianças com paralisia cerebral.

Cottalorda, Gautheron, Metton, Charmet e Chavier ${ }^{32}$ chegaram a conclusões similares num estudo de caso único numa criança com lesão cerebral. Porém, após cerca de 18 meses sem utilização de imobilização gessada, registou-se uma recorrência da deformidade em equino.

Apesar de Brouwer, Wheeldon e Stradiotto-Parker ${ }^{33}$ terem constado, num estudo realizado em crianças com paralisia cerebral, que, após uma imobilização gessada de três semanas, os flexores plantares não apresentavam alteração da força muscular, é amplamente reconhecido que a imobilização prolongada pode levar à fraqueza muscular, com consequente alteração da função e da marcha ${ }^{34,35,36,37}$, sendo, como tal, contra-indicada a utilização de gessos por tempos muito prolongados.

Por fim, devemos referirmo-nos igualmente à utilização de talas e ortóteses, as quais permitem a manutenção do segmento numa 
posição de alongamento por períodos variavelmente longos, promovendo o alinhamento segmentar $e$ postural. Não devemos esquecer a prolífica quantidade de literatura dedicada às ortóteses e material ortopédico complexo destinado à correcção postural e de deformidades específicas. A análise da literatura respeitante a esse tipo de material não compreende um objectivo deste artigo. No entanto, apresentamos, de seguida, alguns estudos relativos à utilização de ortóteses simples com vista ao tratamento de contraturas (tabela 1). Mudanças plásticas em tecidos contrácteis e não contrácteis podem ser a base das melhorias "permanentes" ou a longo prazo na flexibilidade $^{22}$. Quando os músculos são mantidos numa posição alongada durante várias semanas são acrescentados sarcómeros em série $^{3,4}$. Quando tecidos conectivos não contrácteis são alongados com uma força de alongamento prolongada de baixa intensidade, ocorre deformação plástica e o comprimento tecidular aumenta ${ }^{4,42,43}$.

\section{Estiramento mecânico cíclico}

Starring et al ${ }^{44}$ usou o termo estiramento cíclico para descrever um tipo de alongamento repetitivo aplicado por meio de um dispositivo mecânico. Os autores compararam a utilização de um alongamento cíclico, usando uma força mecânica de alongamento de 10 segundos no final da amplitude seguido de um breve repouso, com um estiramento mecânico estático. $A$ intensidade da força de alongamento era limitada pelo nível de tolerância do doente e pela habilidade para se manter relaxado. Os procedimentos de alongamento foram aplicados aos músculos ísquiotibiais de participantes saudáveis durante $15 \mathrm{mi}-$ nutos por dia ao longo de cinco dias

\begin{tabular}{|c|c|c|c|}
\hline Autores & Amostra & Tipo de ortótese & Efeito \\
\hline Bonnuti et al. ${ }^{38}$ & $\begin{array}{l}\text { Adultos com } \\
\text { contratura do } \\
\text { cotovelo (flexum) }\end{array}$ & $\begin{array}{l}\text { Ortótese de extensão } \\
\text { do cotovelo }\end{array}$ & $\begin{array}{l}\text { Melhoria na ampli- } \\
\text { tude de extensão } \\
\text { do cotovelo em } \\
\text { todos os indivíduos }\end{array}$ \\
\hline Steffen e Mollinger ${ }^{39}$ & $\begin{array}{l}\text { Crianças com } \\
\text { diplegia espástica } \\
\text { [encurtamento dos } \\
\text { ísquiotibiais e } \\
\text { tricípete sural] }\end{array}$ & $\begin{array}{l}\text { Ortótese acima } \\
\text { do joelho }\end{array}$ & $\begin{array}{l}\text { Efeitos positivos } \\
\text { após } 5 \text { meses de } \\
\text { utilização ( } 3 \text { horas } \\
\text { por dia, } 5 \text { dias por } \\
\text { semana) }\end{array}$ \\
\hline James et $\mathrm{al}^{40}$ & $\begin{array}{l}\text { Crianças com } \\
\text { paralisia cerebral } \\
\text { (encurtamento } \\
\text { dos ísquiotibiais } \\
\text { e tricípete sural] }\end{array}$ & $\begin{array}{l}\text { Ortótese acima } \\
\text { do joelho }\end{array}$ & $\begin{array}{l}\text { Efeitos positivos } \\
\text { com utilização } \\
\text { durante } 3 \text { meses, } \\
\text { uma hora por dia, } \\
7 \text { dias por semana }\end{array}$ \\
\hline Gelinas et $\mathrm{al}^{41}$ & $\begin{array}{l}22 \text { adultos com } \\
\text { AVC (contratura } \\
\text { do cotovelo) }\end{array}$ & $\begin{array}{l}\text { Ortótese de } \\
\text { extensão e de flexão }\end{array}$ & $\begin{array}{l}11 \text { dos } 22 \text { indi- } \\
\text { víduos tiveram au- } \\
\text { mento da amplitude } \\
\text { de movimento } \\
{\left[30^{\circ}-130^{\circ}\right]}\end{array}$ \\
\hline
\end{tabular}

TABELA1

Alguns estudos realizados acerca da utilização de ortóteses no tratamento de contraturas.

consecutivos. Foram registados aumentos significativos na extensibilidade dos ísquiotibiais mais significativos no método cíclico de estiramento, quando foi tida em conta a análise de variáveis precisas.

Para além disso, os participantes relataram que o alongamento cíclico era mais confortável e mais tolerável que o alongamento mantido. Este estudo sobre o alongamento cíclico demonstra a importância de impor um alongamento prolongado sobre os músculos retraídos e o tecido conectivo de modo a se conseguir uma deformação plástica $\mathrm{e}$ alongamento eficaz dos tecidos. 0 alongamento prolongado é mais indicado de modo a se conseguirem ganhos a longo prazo na amplitude de movimento.

0 alongamento mecânico prolongado, seja cíclico ou mantido, parece ser mais efectivo que o alongamento passivo manual porque a força de alongamento é aplicada durante muito mais tempo do que seria suportável e viável com o alongamento manual'.

\section{Inibição activa}

A inibição activa refere-se a técnicas nas quais o paciente relaxa reflexamente o músculo a ser alongado antes da manobra de alongamento. Isso pode ser conseguido através de técnicas/princípios de Facilitação Neuromuscular Proprioceptiva (PNF) ou através do estiramento activo.

\section{Estiramento activo}

É o tipo de estiramento em que o sujeito alonga o músculo ou grupo muscular por meio da contracção dos músculos "antagonistas" a estes. Este tipo de estiramento põe em evidência os princípios da inibição recíproca: a contracção de determinado músculo ou conjunto 


\begin{tabular}{|c|c|c|}
\hline Autores & Amostra/Métodos & Efeitos \\
\hline Sady et al. ${ }^{49}$ & $\begin{array}{l}\text { Grupo controlo }(n=10) \text {; Estiramentos } \\
\text { balísticos }(n=11) ; \text { Estiramentos estáticos } \\
(n=10) \text { e PNF }(n=12) .3 \text { dias/semana, } \\
6 \text { semanas de programa }\end{array}$ & $\begin{array}{l}\text { Melhores resultados com } \\
\text { PNF do que com outros } \\
\text { métodos e mais nos } \\
\text { músculos ísquiotibiais }\end{array}$ \\
\hline Lucas e Koslow ${ }^{50}$ & $\begin{array}{l}\text { N=63, universitários; Estiramentos } \\
\text { estáticos, dinâmicos e PNF sobre } \\
\text { músculos ísquiotibiais e gémeos. } \\
\text { 3xsemana, } 21 \text { dias }\end{array}$ & $\begin{array}{l}\text { Todos os métodos pro- } \\
\text { duziram resultados no } \\
\text { aumento das amplitudes }\end{array}$ \\
\hline Wallin et $\mathrm{al}^{51}$ & $\begin{array}{l}\mathrm{N}=47 \text { (sexo masculino); } 4 \text { grupos: } 3 \\
\text { grupos com contract-relax modificado } \\
\text { ( } \mathrm{n}=10 \text { para cada, } 1 \mathrm{x}, 2 \mathrm{x} \text { e } 3 \mathrm{x} / \text { semana) } \\
\text { e } 1 \text { grupo com estiramentos balísticos; } \\
30 \text { dias de programa }\end{array}$ & $\begin{array}{l}\text { Contract-relax melhor } \\
\text { que estiramentos } \\
\text { balísticos. Melhores } \\
\text { resultados com maior } \\
\text { frequência de treino }\end{array}$ \\
\hline Cornelius et $\mathrm{al}^{52}$ & $\begin{array}{l}\text { N=120 (sexo masculino); } 4 \text { grupos: } \\
3 \text { grupos com PNF modificado (PCP, } \\
\text { 3-PIECP e 3-PIFCP) e } 1 \text { grupo com } \\
\text { estiramento passivo }\end{array}$ & $\begin{array}{l}\text { Maior amplitude de } \\
\text { movimento observada } \\
\text { nos grupos de PNF }\end{array}$ \\
\hline
\end{tabular}

TABELA2

Estudos clássicos sobre os efeitos do PNF na amplitude de movimento.

de músculos provoca o relaxamento do músculo ou músculos que estão a ser alongados. É um tipo de estiramento diferente do estiramento passivo, sendo que é impossivel obter-se uma deformação adicional com este tipo de estiramento, e como tal, não produz os mesmos resultados que o estiramento com apoio manual ou mecânico ${ }^{45}$.

Por outro lado, o estudo de Winters et $\mathrm{al}^{46}$, o qual comparou o efeito do estiramento passivo e do estiramento activo sobre a flexibilidade dos flexores da anca em indivíduos com limitação da extensão da anca, determinou que tanto o estiramento activo como o estiramento activo produziram resultados análogos em termos do aumento da amplitude extensora. Os autores referem que tal pode ser devido à facilidade de ganho de amplitude por parte de tal grupo muscular (flexores da anca), sendo que, provavelmente, os resultados poderiam ser muito diferentes se 0 grupo testado constituísse por exemplo os ísquiotibiais.

\section{Técnicas de Facilitação}

Neuromuscular Proprioceptiva

O PNF clássico ou tradicional supõe a realização de um treino mediante a realização de padrões diagonais de movimento, nos quais intervêm princípios como a facilitação motora, o contacto manual preciso e a resistência máxima ${ }^{47}$.

Assim sendo, quando nos referimos ao PNF como forma de trabalho de flexibilidade, não estamos na realidade a referenciar o PNF clássico, mas sim técnicas específicas do PNF, que fazem uso da fisiologia dos órgãos tendinosos de Golgi.

Clinicamente os terapeutas têm assumido que a contracção antes do alongamento leva a um relaxamento reflexo acompanhado por uma diminuição na actividade electromiográfica no músculo retraído". Pelo facto de, mediante a activação do reflexo tendinoso de Golgi ou reflexo miotático inverso, as estruturas musculares relaxarem após a sua contracção, tanto o hold-relax quanto o contract-relax têm sido continuamente estudados, muitas vezes comparativamente a outras técnicas de estiramento, no respeitante ao ganho de amplitude de movimento.

Se o relaxamento muscular tem sido referido continuamente como a razão pela qual existe um maior progresso na amplitude de movimento com a utilização do PNF, veremos mais tarde, quando falarmos de outras formas de relaxamento muscular (ex. calor) e do paradoxo do Coeficiente de elasticidade, que é possível que tudo o que tem sido até agora aceite de forma muitas vezes acrítica esteja errado.

Importa referir o artigo de Chalmers ${ }^{48}$, que aponta para questões de grande relevância relativamente à base teorética da utilização do PNF como forma de estiramento. $\mathrm{O}$ autor estudou minuciosamente a teoria neurofisiológica das técnicas de estiramento de PNF. Os dados obtidos não suportam a acepção clássica de que as técnicas de PNF, nomeadamente da contracção prévia do músculo a estirar, produzam o relaxamento da musculatura estirada. Na realidade, a seguir à contracção do músculo a estirar, a resposta de inibição do reflexo tónico de estiramento dura somente um segundo. Segundo os dados do autor, a diminuição da resposta do músculo a estirar (relativamente ao reflexo miotático) a seguir à contracção muscular não é devida à activação dos órgãos tendinosos de Golgi, como tem sido comummente aceite, mas sim devido à existência de um prévio mecanismo de inibição pré-sináptica do sinal sensorial do fuso neuromuscular. Assim sendo, a deformação adicional adviria não da acção do reflexo tendinoso de Golgi e posterior relaxamento tecidular, mas sim da mera inibição do reflexo de Hoff- 
mann, permitindo, como tal, uma maior progressão em termos de amplitude articular. Para além das explicações de natureza neurofisiológica, o autor, referindo que estas são provavelmente insuficientes para explicar os resultados obtidos com o PNF, aponta para explicações de outras naturezas, como por exemplo, o facto de o estiramento com PNF ser mais tolerável para o doente ou desportista.

Não fazemos, no entanto, grandes considerações sobre os possiveis mecanismos visco-elásticos envolvidos no PNF. Isto porque, sendo que as estruturas moles se apresentam como mais relaxadas após a contracção do músculo a estirar, entramos mais uma vez no paradoxo do Coeficiente de elasticidade, o qual, como veremos, aponta para uma ausência de vantagens no aumento da amplitude de movimento com o aumento directo da elasticidade muscular.

Sendo assim, consideramos que os efeitos do PNF serão de natureza fundamentalmente neurofisiológica e não muscular, mesmo que o processo seja diferente daquilo que até agora tem sido considerado.

Não obstante as razões pelas quais o PNF fornece os seus resultados, apresentamos seguidamente diversos estudos encontrados na literatura que apresentam essa evidência, para além de compararem as técnicas de PNF com outras de estiramento muscular (tabelas 2 e 3 ). Dos estudos apresentados, podemos constatar que houve um progresso nas metodologias desde as investigações mais antigas até às mais recentes. Em termos gerais, observa-se a existência de grandes vantagens na utilização do PNF em termos do aumento da amplitude de movimento. Estas vantagens tendem a ser maiores na técnica

\begin{tabular}{|c|c|c|}
\hline Autores & Amostra/Métodos & Efeitos \\
\hline Spernoga et al ${ }^{53}$ & $\begin{array}{l}\mathrm{N}=30 \text { (sexo masculino]; } 2 \text { grupos: um } \\
\text { grupo controlo e um grupo experimental. } \\
\mathrm{O} \text { grupo experimental recebeu cinco } \\
\text { estiramentos de hold-relax modificado }\end{array}$ & $\begin{array}{l}\text { A sequência de cinco } \\
\text { estiramentos de hold-relax } \\
\text { produziram mais resultados } \\
\text { na flexibilidade dos ísquio- } \\
\text { tibiais, que se mantiveram } \\
\text { durante seis minutos depois } \\
\text { de finalizado o protocolo }\end{array}$ \\
\hline Ferber et $\mathbf{a l}^{54}$ & $\begin{array}{l}24 \text { adultos; } 3 \text { grupos: } \\
\text { estiramentos estáticos, contract-relax } \\
\text { e contract-relax do agonista }\end{array}$ & $\begin{array}{l}\text { Método agonist contract- } \\
\text {-relax com melhores } \\
\text { resultados de amplitude } \\
\text { de movimento e maior } \\
\text { actividade electromiográfica. } \\
\text { Porém, os efeitos não pare- } \\
\text { cem ter-se devido ao relaxa- } \\
\text { mento do músculo estirado }\end{array}$ \\
\hline Rowlands et al ${ }^{55}$ & $\begin{array}{l}43 \text { raparigas; } 3 \text { grupos: } 1 \text { grupo com } \\
\text { PNF + } 5 \text { contracções isométricas, } \\
1 \text { grupo com PNF + } 10 \text { contracções } \\
\text { isométricas e grupo controlo }\end{array}$ & $\begin{array}{l}\text { Melhores resultados nos } \\
\text { grupos PNF relativamente ao } \\
\text { controlo. Um maior número } \\
\text { de contracções isométricas } \\
\text { no PNF produz maiores } \\
\text { ganhos de flexibilidade }\end{array}$ \\
\hline Feland et $\mathrm{al}^{56}$ & $\begin{array}{l}\text { N=72 (sexo masculino); } 4 \text { grupos: } \\
1 \text { grupo controlo, } 1 \text { grupo PNF com } \\
1,20 \% \text { de contracção isométrica, } \\
1 \text { grupo PNF com } 2,60 \% \text { de contracção } \\
\text { isométrica e } 1 \text { grupo PNF com 100\% } \\
\text { de contracção isométrica }\end{array}$ & $\begin{array}{l}\text { Os grupos PNF apresentaram } \\
\text { todos melhores resultados de } \\
\text { amplitude de movimento dos } \\
\text { ísquiotibiais que o grupo } \\
\text { controlo. Não se verificaram } \\
\text { diferenças entre os diversos } \\
\text { grupos PNF - contract-relax } \\
\text { (diferentes níveis de contracção) }\end{array}$ \\
\hline Davis et $\mathrm{al}^{57}$ & $\begin{array}{l}19 \text { jovens adultos; } 4 \text { grupos: Grupo } 1 \\
\text { ( } n=5 \text { ) realizou auto-alongamento, Grupo } 2 \\
(n=5) \text { realizou estiramentos estáticos, } \\
\text { grupo } 3 \text { ( } n=5 \text { ) utilizou PNF e grupo } 4 \text { é o } \\
\text { grupo de controlo. Todos os grupos expe- } \\
\text { rimentais receberam estiramentos de } 30 \\
\text { segundos, 3xsemana, durante } 4 \text { semanas }\end{array}$ & $\begin{array}{l}\text { Em todos os grupos expe- } \\
\text { rimentais houve aumento da } \\
\text { amplitude de movimento dos } \\
\text { ísquiotibiais para além da } \\
\text { linha de base. Mas somente } \\
\text { o grupo dos estiramentos } \\
\text { estáticos apresentou } \\
\text { resultados significativos } \\
\text { quando comparados com } \\
\text { o grupo de controlo }\end{array}$ \\
\hline Decicco e Fisher ${ }^{58}$ & $\begin{array}{l}30 \text { participantes (ambos os sexos] foram } \\
\text { divididos em } 3 \text { grupos ( } \mathrm{n}=10 \text { para cada): } \\
\text { grupo PNF contract-relax, grupo PNF hold- } \\
\text {-relax e grupo de controlo. Programa } 2 x \\
\text { por semana, } 6 \text { semanas }\end{array}$ & $\begin{array}{l}\text { Melhoria na amplitude de } \\
\text { movimento do ombro nos } \\
\text { grupos experimentais } \\
\text { relativamente ao grupo de } \\
\text { controlo. } 0 \text { grupo contract- } \\
\text {-relax obteve ganhos de am- } \\
\text { plitude ligeiramente supe- } \\
\text { riores ao grupo hold-relax } \\
\left(0,30^{\circ} \text { de diferença) }\right.\end{array}$ \\
\hline
\end{tabular}
na amplitude de movimento. 


\begin{tabular}{|c|c|c|}
\hline Autores & Amostra/Métodos & Efeitos \\
\hline Williford et $\mathrm{al}^{67}$ & $\begin{array}{l}51 \text { estudantes; } 3 \text { grupos: um grupo que } \\
\text { correu e depois realizou estiramentos, um } \\
\text { grupo que só realizou estiramentos e um } \\
\text { grupo de controlo. Testes realizados para } \\
\text { as amplitudes do ombro, ísquiotibiais, } \\
\text { tronco e anca antes e depois de } 9 \text { semanas }\end{array}$ & $\begin{array}{l}\text { Os resultados não suportam } \\
\text { a ideia de que o aquecimento } \\
\text { dos músculos antes dos es- } \\
\text { tiramentos resulta em maio- } \\
\text { res amplitudes de movimento }\end{array}$ \\
\hline $\begin{array}{l}\text { Cornelius } \\
\text { e Hands }{ }^{68}\end{array}$ & $\begin{array}{l}\mathrm{N}=54 \text { (sexo feminino); } 2 \text { grupos realizaram } \\
\text { aquecimento (exercícios) e um grupo de } \\
\text { controlo. Após o aquecimento, todos os } \\
\text { grupos efectuaram treino de estiramentos } \\
\text { mediante PNF modificado }\end{array}$ & $\begin{array}{l}\text { Não se registaram } \\
\text { diferenças nas amplitudes } \\
\text { articulares comparando os } \\
\text { grupos de aquecimento com } \\
\text { o grupo de controlo }\end{array}$ \\
\hline Burke et al $^{69}$ & $\begin{array}{l}\mathrm{N}=45 \text { ( } 18-25 \text { anos de idade); } 3 \text { grupos que } \\
\text { efectuaram treino de flexibilidade com PNF: } \\
\text { um grupo controlo, um grupo após } 10 \\
\text { minutos de imersão em água fria e um } \\
\text { grupo após imersão em água quente. } \\
5 \text { dias de procedimento }\end{array}$ & $\begin{array}{l}\text { Todos os grupos } \\
\text { apresentaram melhorias } \\
\text { no comprimento muscular } \\
\text { dos ísquiotibiais. Não se } \\
\text { encontraram diferenças } \\
\text { entre os grupos }\end{array}$ \\
\hline Knight et al $^{70}$ & $\begin{array}{l}\text { N=97 (idade média de } 27,6 \text { anos), } \\
\text { limitações na flexão dorsal do tornozelo. } \\
5 \text { grupos: grupo } 1 \text { - grupo de controlo, } \\
\text { não realizou o protocolo de estiramentos; } \\
\text { os grupos experimentais realizaram um } \\
\text { protocolo de estiramentos } 3 x \text { semana, } \\
\text { durante } 6 \text { semanas: grupo } 2 \text { - só estira- } \\
\text { mentos; grupo } 3 \text { - exercício activo antes } \\
\text { dos estiramentos; grupo } 4 \text { - calor superficial } \\
\text { antes dos estiramentos; grupo } 5 \text { - ultra-sons } \\
\text { modo contínuo durante sete min. antes } \\
\text { dos estiramentos. }\end{array}$ & $\begin{array}{l}\text { Todos os grupos experi- } \\
\text { mentais apresentaram uma } \\
\text { melhoria na amplitude activa } \\
\text { e passiva de movimento. } \\
\text { O grupo que realizou } \\
\text { ultra-sons prévios ao } \\
\text { protocolo de estiramentos } \\
\text { teve os maiores ganhos } \\
\text { de flexibilidade }\end{array}$ \\
\hline
\end{tabular}

de Weijer et al $^{71} \quad \mathrm{~N}=56$ (18-42 anos de idade), com limitação Um aumento na amplitude dos ísquiotibiais. 4 grupos: (1) aquecimento dos ísquiotibiais foi obtido (exercícios) e estiramento estático, (2) nos grupos do estiramento. apenas estiramento estático, (3) apenas Não se verificaram diferenças aquecimento (exercícios), (4) grupo controlo com a realização de exercício prévio aos estiramentos

\begin{tabular}{|c|c|c|}
\hline Draper et $\mathrm{al}^{72}$ & $\begin{array}{l}\mathrm{N}=30 \text { (idade média de } 21,5 \text { anos), } \\
\text { com ísquiotibiais encurtados. } 3 \text { grupos: } \\
\text { diatermia + estiramentos, diatermia } \\
\text { simulada + estiramentos, grupo controlo }\end{array}$ & $\begin{array}{l}\text { Melhoria na amplitude } \\
\text { dos ísquiotibiais no grupo } \\
\text { diatermia + estiramentos }\end{array}$ \\
\hline Wenos e Konin ${ }^{73}$ & $\begin{array}{l}\mathrm{N}=12 \text { (idade média de } 25,3 \text { anos); } \\
\text { Um grupo com aquecimento activo e um } \\
\text { grupo com aquecimento passivo (calor } \\
\text { superficial), ambos realizaram posterior- } \\
\text { mente estiramentos através de PNF }\end{array}$ & $\begin{array}{l}0 \text { grupo que efectuou } \\
\text { aquecimento activo teve os } \\
\text { melhores resultados em } \\
\text { termos de flexibilidade }\end{array}$ \\
\hline Zakas et $\mathrm{al}^{74}$ & $\begin{array}{l}\mathrm{N}=18 \text {, adolescentes; } 3 \text { grupos: um grupo } \\
\text { realizou aquecimento, um grupo realizou } \\
\text { aquecimento + estiramentos passivos e } \\
\text { o último grupo realizou somente } \\
\text { estiramentos passivos }\end{array}$ & $\begin{array}{l}\text { Melhorias na flexibilidade } \\
\text { nos grupos que realizaram } \\
\text { estiramentos. } 0 \text { grupo que } \\
\text { realizou aquecimento antes } \\
\text { dos estiramentos não apre- } \\
\text { senta melhores resultados }\end{array}$ \\
\hline
\end{tabular}

TABELA4

Estudos sobre o efeito do calor no treino de flexibilidade. contract-relax e quando são realizadas contracções isométricas mais prolongadas.

Em alguns estudos começa já a questionar-se se a base dos resultados está realmente na produção de um maior relaxamento no músculo a estirar, ou seja, naquele que produziu contracção. Se a base dos resultados estiver somente na obtenção de um maior relaxamento muscular, é de esperar que a realização de estiramentos em músculos previamente aquecidos resulte também em resultados observáveis na amplitude de movimento. É disso que iremos falar de seguida.

\section{0 calor no treino da flexibilidade}

0 aquecimento do tecido mole realizado antes do alongamento permitirá aumentar a extensibilidade dos tecidos encurtados. Músculos aquecidos relaxam e alongam-se mais facilmente, tornando o alongamento mais confortável para o paciente. À medida que a temperatura do músculo aumenta, a quantidade de força requerida para alongar os tecidos contrácteis e não contrácteis e o tempo durante o qual a força de alongamento precisa de ser aplicada diminuem. Com o aumento da temperatura intramuscular, o tecido conectivo cede mais facilmente ao alongamento e a sensibilidade dos órgãos tendinosos de Golgi aumenta (o que leva a uma maior inibição muscular) ${ }^{59}$.

Para além disso, o aquecimento também minimiza a probabilidade de microtraumas aos tecidos moles durante o alongamento e, desse modo, pode diminuir a dor muscular tardia que ocorre após os exercícios ${ }^{60,61,62,63}$.

$\mathbf{O}$ aquecimento pode ser conseguido com calor superficial ou profundo aplicado aos tecidos moles antes 
ou durante o alongamento. Exercícios de baixa intensidade feitos antes do alongamento aumentarão a circulação para os tecidos moles e aquecerão os tecidos a serem alongados. Embora os resultados dos estudos possam diferir, uma caminhada curta, exercícios não fatigantes em bicicleta estacionária ou alguns minutos de exercícios activos para os membros superiores podem ser usados para aumentar a temperatura intramuscular antes de se iniciar actividades de alongamento ${ }^{64,65,66}$.

Sendo assim, seja através do aquecimento directo, seja por meio de exercícios de aquecimento, o alongamento deve, segundo os argumentos precedentes, que são na realidade clássicos argumentos coerentes, ser precedido de aquecimento.

Veremos, de seguida, que todo o conteúdo anteriormente explanado é fundamentalmente teorético e especulativo. Neste momento do artigo, a opção mais legítima de desenvolvimento conteudístico será apresentarmos uma sinopse dos estudos efectuados acerca do efeito do aquecimento no treino de flexibilidade e ganho de amplitude de movimento (tabela 4).

Pela observação da tabela 4 , é possivel constatar que há dois estudos que apontam para melhores resultados na flexibilidade por se realizar uma forma de aquecimento profundo (Knight et $\mathrm{al}^{70}$, Draper et $\mathrm{al}^{72}$ ) e um estudo que aponta para resultados semelhantes no respeitante à realização de aquecimento activo (Wenos e $\mathrm{Konin}^{73}$ ). De resto, todos os outros estudos infirmam aquilo que classicamente tem sido admitido, ou seja, que $o$ aquecimento prévio ao treino de flexibilidade melhora o nível permanente de deformação muscular.
É, no mínimo, uma questão que tem de ser estudada com mais afinco. Por outro lado, devemos questionar se um possível efeito do calor na flexibilidade estará só relacionado com o relaxamento tecidular, ou se não estará relacionada com factores de natureza neuromuscular. E a mesma questão se aplica no respeitante aos diferentes métodos e técnicas de relaxamento global, ou a técnicas mais específicas como a massagem, seja realizada de forma autónoma, seja realizada previamente ao treino de flexibilidade. Contudo, a questão do relaxamento produzido através do calor, da massagem ou do PNF, se é mesmo de relaxamento que se trata, expressa-se num aumento da elasticidade muscular, algo que, como veremos de seguida, é controverso no respeitante ao aumento da flexibilidade a longo prazo.

\section{O paradoxo do Coeficiente de elasticidade}

Classicamente, tem sido considerado que os efeitos do PNF, do aquecimento prévio, da massagem e até mesmo dos fármacos mio-relaxantes são comuns no que implicam de relaxamento dos músculos a serem estirados. 0 relaxamento expressa-se num aumento da elasticidade muscular, e esse aumento implica uma maior deformação a curto termo. Tem sido assumido que esta mesma deformação num tempo imediato resulta num maior ganho de flexibilidade em termos mais permanentes. Porém, tal pode estar longe da realidade.

Tudo se resume à fórmula de fluage muscular, que passamos a rever:

Índice de deformação =

Força aplicada / Coeficiente de elasticidade $x$ Tempo
Acontece que quanto maior o Coeficiente de elasticidade, ou seja, quanto mais elástico o corpo é, menos comprimento ele ganhará. O Índice de deformação ou fluage muscular depende proporcionalmente da força e tempo de estiramento. Porém, se a elasticidade for maior, algo que poderá ser conseguido à custa do relaxamento das fibras musculares, então a verdadeira deformação tecidular ou o ganho permanente de amplitude é menor. Quanto mais rígido um corpo estiver maior o ganho de amplitude este mesmo corpo obterá.

Citando Souchard ${ }^{16}$, aliás um dos poucos visionários desta questão, "as implicações práticas do paradoxo vigente são interessantes, pois isto significa que qualquer aquecimento muscular, melhorando artificial e provisoriamente a flexibilidade, aumenta o Coeficiente de elasticidade. $\mathbf{O}$ músculo dará a impressão de alongar-se com mais facilidade, mas, após o alongamento, o comprimento ganho será menor. É, portanto, 'a frio' que se deve proceder aos alongamentos" (p. 90).

Isto pode explicar a falta de evidência relativa à eficácia dos métodos de aquecimento e relaxamento prévios ao treino de estiramento no aumento da flexibilidade dos tecidos musculares. Por outro lado, no respeitante ao PNF, já vimos que é muito provável que os resultados obtidos com o método possam não ser devidos ao relaxamento produzido no músculo a estirar (se é que se produz algum tipo de relaxamento mediante a realização dessas técnicas) mas sim devidos a mecanismos neuromusculares precisos (como a inibição do reflexo de Hoffmann); eventualmente, alguns destes mecanismos também poderão estar presentes aquando da utilização de outras técnicas, como a massagem. 


\section{CONCLUSÃO}

A investigação em torno da temática da flexibilidade está longe de ser suficiente, ao contrário do que possamos especular. Os mecanismos neurofisiológicos e musculares que regem a teoria implicada no treino de flexibilidade estão, muitas vezes, em contradição, sendo que, por um lado, certos mecanismos neuromusculares poderão explicar a efectividade de certas técnicas de estiramento, e por outro, o paradoxo do Coeficiente de elasticidade leva-nos a questionar certos modelos classicamente aceites e a aceitar métodos e formas de trabalho menos preconizados.

Dentro das diversas modalidades de estiramento muscular, os protocolos efectivados estarão dependentes, em última análise, do que for considerado pelo terapeuta ou instrutor o mais sensato para cada caso. Por outro lado, não restam dúvidas relativamente a certos dados, valores e parâmetros, sendo que é certo, por exemplo, que o estiramento controlado, prolongado e sem dor é preferivel ao estiramento balístico e sem controlo.

\section{CORRESPONDÊNCIA}

Luís Filipe dos Santos Coelho

Av. Coronel Eduardo Galhardo, n. ${ }^{\circ} 28,5 \circ$ dto

1170-105 Lisboa - Portugal

Contacto: 963304478

E-mail: coelholewis@gmail.com

\section{REFERÊNCIAS}

1. Kisner C; Colby L (1998). Exercícios terapêuticos: fundamentos e técnicas ( $3^{\underline{a}}$ edição). São Paulo: Editora Manole Ltda.
2. Flitney FW; Hirst DG (1978). Cross bridge detachment and sarcomere "give" during stretch of active frog's muscle. $J$ Physiol 276 : :449-465.

3. Tardieu C; Tabary JC; Tabary C; Tardieu G (1982). Adaptation of connective tissue length to immobilization in the lengthened and shortened position in cat soleus muscle. J Physio/(Paris) 78:214-220.

4. Threlkeld AJ (1992). The effects of manual therapy on connective tissue. Phys Ther 72:893-902.

5. Tillman LJ; Cxummings GS (1992). Biologic mechanisms of connective tissue mutability. In: Currier DP; Nelson RM [Eds.]. Dynamics of human biologic tissues. Philadelphia: FA Davis.

6. Etnyre BR; Abraham LD (1986). Gains in range of ankle dorsiflexion using three popular stretching techniques. Am J Phys Med65:189-196.

7. Madding SW et al. (1987). Effect of duration of passive stretch on hip abduction range of motion. $J$ Orthop Sports Phys Ther 8:409.

8. Bandy WD; Irion JM (1994). The effect of time on static stretch on the flexibility of the hamstrings muscles. Phys Ther 74(9):845-850.

9. Bandy WD; Irion JM; Briggler M (1998). The effect of time and frequency of static stretching on flexibility of the hamstrings muscles. Phys Ther 77(10):1090-1096.

10. Roberts JM; Wilson K (1999). Effect of stretching duration on active and passive range of motion in the lower extremity. $B r J$ Sports Med 33(4):259-263.

11. Feland JB; Myrer JW; Schulthies SS; Fellingham GW; Measom GW (2001). The effect of duration of stretching of the hamstrings muscle group for increasing range of motion in people aged 65 years or older. Phys Ther 81(5):1110-1117.
12. Loannis T; Christos G; Nikolaos Z; Aikaterini V; Efstratios V (2005). The effect of stretching duration on the flexibility of lower extremities in junior soccer players. Physical Training September.

13. Bertherat T (1976). Le corps a ses raisons. Auto-Guerison et anti-gymnastique. Paris: Seuil.

14. Souchard Ph-E (2004). Stretching global activo: de la perfección muscular al éxito deportivo II ( $3^{\underline{a}}$ ed.). Barcelona: Paidotribo.

15. Busquet L (1998). Les chaînes musculaires (3ème éd. revue et complétée) (v. 2: Lordoses, cyphoses, scolioses et déformations thoraciques]. Paris: Frison-Roche.

16. Souchard Ph-E (2003). As escolioses. Seu tratamento fisioterapêutico e ortopédico. São Paulo: É Realizações.

17. Cummings GS; Tillman LJ (1992). Remodelling of dense connective tissue in normal adult tissues. In: Currier DP, Nelson RM [Eds.]. Dynamics of human biologic tissues. Philadelphia: FA Davis.

18. Walker SM (1961). Delay of twitch relaxation induced by stress and stress relaxation. $J$ Appl Physiol 16:801.

19. Smith LL; Brunetz MH; Chenier TC; McCammon MR; Houmard JA; Franklin ME; Israel RG (1993). The effects of static and ballistic stretching on delayed onset muscle soreness and creatine kinase. Res Q Exerc Sport 64(1):103-107.

20. Nelson AG; Kokkonen J (2001). Acute ballistic muscle stretching inhibits maximal strength performance. Res Q Exerc Sport 72(4): :415-419.

21. Unick J; Kieffer HS; Cheesman W; Feeney A (2005). The acute effects of static and ballistic stretching on vertical jump performance in trained women. $J$ Strenght Cond Res 19(1):206-212. 
22. Bohannon RW (1984). Effect of repeated eight minute muscle loading on the angle of straight leg raising. Phys Ther 64:491.

23. Kottke F (1971). Therapeutic exercise. In: Krusen F; Kottke F; Ellwood M (Eds.). Handbook of physical medicine and rehabilitation, $2^{\text {nd }}$ edition. Philadelphia: Saunders. 24. Sapega A et al. (1981). Biophysical factors in range of motion exercises. The Physician and Sportsmedicine 9:57.

25. Godges JJ et al. (1989). The effects of two stretching procedures on hip range of motion and gait economy. J Ortho Sport Phys Ther 10(9):350-356.

26. Bohannon RW; Larkin PA (1985). Passive ankle dorsiflexion increases in patients after a regimen of tilt table: wedge board standing. Phys Ther 65:1676.

27. Hepburn G; Crivelli K (1984). Use of elbow Dynasplint for reduction of elbow flexion contracture: a case study. J Orthop Sports Phys Ther 5:269.

28. Cottarola J; Gautheron V; Metton G; Charmet E; Chavier Y (2000). Toe walking in children younger than six years with cerebral palsy - The contribution of serial corrective casts. J Bone joint Surg 82 : :541-544.

29. Booth B; Doyle M; Montgomery J (1983). Serial casting for the management of spasticity in the head injured adult. Phys Ther 63:1960$-1966$.

30. Cusick B (1990). Serial casts an approach to management of static soft tissue contracture. In: Progressive casting and splinting for lower extremity deformities in Children with neuromotor dysfunction. Arizona: Arizona Therapy Skill Builders, pp. 265-311.
31. Ada L; Canning (1990). Key Issues in neurological physiotherapy. Oxford: Butterworth Heinemann.

32. Cottarola J; Gautheron V; Metton G; Charmet E; Chavier Y (2000). Toe walking in children younger than six years with cerebral palsy - The contribution of serial corrective casts. JBone joint Surg 82:541-544.

33. Brouwer B; Wheeldon R; Stradiotto-Parker N; Album J (1998). Reflex excitability and isometric force production in cerebral palsy: the effect of serial casting. Dev Med Child Neurol 40:168-175.

34. Carr J; Shepherd R; Ada L (1995). Spasticity: Research findings and implications for intervention. Physiot 81(8):421-429.

35. Boyd R; Ada L (2001). Physiotherapy management of spasticity. In: Barnes M, Johnson G (Eds.). Upper motor neurone syndrome and spasticity: Clinical management and neurophysiology. Cambridge: Cambridge University Press, p. 142. 36. Richardson D (2002). Physical Therapy in spasticity. Eur J Neur 9 suppl:17-22.

37. Farmer S; James M (2001). Contractures in orthopaedic and neurological conditions: a review of causes and treatment. Disab Rehab 23(13):549-558.

38. Bonutti P; Windau J; Ables B; Miller B (1994). Static progressive stretch to reestablish elbow range of motion. Clin Orthop Rel Res 303: :128-134.

39. Steffen T; Mollinger L (1995). Low-load, prolonged stretch in the treatment of knee flexion contractures in nursing home residents. Phys Ther 75:303-305.

40. James M; Farmer S; Hunt K; Stallard J (1997). Contracture correction using mechanically applied torques: A report to the NHS management executive by Orthotic Research and Locomotor Assessment unit, Oswestry, Shropshire and The Centre for Health Planning and Management. Staffordshire: Keele University.

41. Gelinas J; Faber K; Patterson S; King $\mathbf{G}$ (2000). The effectiveness of turnbuckle splinting for elbow contracture. J Bone Joint Surg 82 : :74-78.

42. Warren CG; Lehmann JF; Koblanski JN (1970). Elongation of rat tail tendon: Effect of load and temperature. Arch Phys Med Rehabil 51:481.

43. Wessling KC; Derane DA; Hylton CR (1987). Effect of static stretch vs. static stretch and ultrasound combined on triceps surae muscle extensibility in healthy women. Phys Ther 67:674.

44. Starring DT; Gossman MR; Nicholson GG Jr; Lemons J (1998). Comparison of cyclic and sustained passive stretching using a mechanical device to increase resting length of hamstring muscles. Phys Ther 68(3):314-320.

45. Van Hatten B (2005). Passive versus active stretching. Phys Ther 85(1):80.

46. Winters MV; Blake CG; Trost JS; Marcello-Brinker TB; Lowe LM; Garber MB; Wainner RS (2005). Passive versus active stretching of hip flexor muscles in subjects with limited hip extension: a randomized clinical trial. Phys Ther 85(1):80.

47. Voss DE; Ionla MK; Myers BJ (1985). Proprioceptive neuromuscular facilitation, $3^{\text {rd }}$ edition. Philadelphia: Harper \& Row.

48. Chalmers G (2004). Re-examination of the possible role of Golgi tendon organ and muscle spindle reflexes in proprioceptive neuromuscular facilitation muscle stretching. Sports Biomech3(1):159-183. 
49. Sady SP; Wortman M; Blanke D (1982). Flexibility training: ballistic, static or proprioceptive neuromuscular facilitation? Arch Phys Med Rehabil 63(6):261-3.

50. Lucas RC; Koslow R (1984). Comparative study of static, dynamic, and proprioceptive neuromuscular facilitation stretching techniques on flexibility. Percept Mot Skills 58(2):615-618.

51. Wallin D; Ekblom B; Grahn R; Nordenbord T (1985). Improvement of muscle flexibility. A comparison between two techniques. Am J Sports Med 13(4):263-268.

52. Cornelius WL; Ebrahim K; Watson J; Hill DW (1992). The effects of cold application and modified PNF stretching techniques on hip joint flexibility in college males. Res Q Exerc Sport 63(3):311-314.

53. Spernoga SG; Uhl TL; Arnold BL; Gansneder BM (2001). Duration of maintained hamstring flexibility after a one-time, modified hold-relax stretching protocol. J Athl Train 36(1):44-48.

54. Ferber R; Osternig L; Gravelle D (2002). Effect of PNF stretch techniques on knee flexor muscle EMG activity in older adults. J Electromyogr Kinesiol 12(5):391-397.

55. Rowlands AV; Marginson VF; Lee $J$ (2003). Chronic flexibility gains: effect of isometric contraction duration during proprioceptive neuromuscular facilitation stretching techniques. Res Q Exerc Sport 74(1):47-51.

56. Feland JB; Marin HN (2004). Effect of submaximal contraction intensity in contract-relax proprioceptive neuromuscular facilitation stretching. $\mathrm{Br} J$ Sports Med 38(4): :E18.
57. Davis DS; Ashby PE; McCale KL; McQuain JA; Wine JM (2005). The effectiveness of 3 stretching techniques on hamstring flexibility using consistent stretching parameters. J Strength Cond Res 19(1):27-32. 58. Decicco PV; Fisher MM (2005). The effects of proprioceptive neuromuscular facilitation stretching on shoulder range of motion in overhand athletes. $J$ Sports Med Phys Fitness 45(2):183-187.

59. Fukami Y; Wilkinson RS (1977). Responses of isolated Golgi tendon organs of the cat. J Physiol 265: :673-689.

60. Henricson AS (1985). The effect of heat and stretching on range of hip motion. J Orthop Sports Phys Ther 6[2]:269.

61. Lentell $\mathbf{G}$ et al. (1992). The use of thermal agents to influence the effectiveness of a low-load prolonged stretch. J Ortho Sports Phys Ther 16[5]:200-207.

62. Zachazewski JE (1989). Improving flexibility. In: Scully RM; Barnes MR [Eds.). Physical Therapy. Philadelphia: JB Lippincott.

63. Zachazewski JE (1990). Flexibility in sports. In: Sanders B (Ed.). Sports Physical Therapy. Norwalk: Appleton \& Lange.

64. Gillette TM (1991). Relationship of body core temperature and warm-up to knee range of motion. J Orthop Sports Phys Ther 13(3): :126-131.

65. Hollis M (1982). Practical exercise therapy $\left(2^{\text {nd }}\right.$ edition]. Oxford: Blackwell Scientific.

66. Smith CA (1994). The warm-up procedure: To stretch or not to stretch. A brief review. J Orthop Sports Phys Ther 19(1):12-17.
67. Williford HN; East JB; Smith $\mathrm{FH}$; Burry LA (1986). Evaluation of warm-up for improvement in flexibility. Am J Sports Med 14(4):316-319.

68. Cornelius WL; Hands MR (1992). The effects of a warm-up on acute hip joint flexibility using a modified PNF stretching technique. J Athl Train 27(2):112-114.

69. Burke DG; Holt LE; Rasmussen R; MacKinnon NC; Vossen JF; Pelham TW (2001). Effects of hot or cold water immersion and modified proprioceptive neuromuscular facilitation flexibility exercise on hamstring length. J Athl Train 36(1):16-19.

70. Knight CA; Rutledge CR; Cox ME; Acosta M; Hall SJ (2001). Effect of superficial heat, deep heat, and active exercise warm-up on the extensibility of the plantar flexors. Phys Ther 81(6):1206-1214.

71. de Weijer VC; Gorniak GC; Shamus $E$ (2003). The effect of static stretch and warm-up exercise on hamstring length over the course of 24 hours. J Orthop Sports Phys Ther 33(12):727-733.

72. Draper DO; Castro JL; Feland B; Schulthies S; Eggett D (2004). Shortwave diathermy and prolonged stretching increase hamstring flexibility more than prolonged stretching alone. $J$ Orthop Sports Phys Ther 34(1):13-20.

73. Wenos DL; Konin JG (2004). Controlled warm-up intensity enhances hip range of motion. $J$ Strength Cond Res 18(3):529-533.

74. Zakas A; Grammatikopoulou MG; Zakas N; Zahariadis P; Vamvakoudis E (2006). The effect of active warm-up and stretching on the flexibility of adolescent soccer players. J Sports Med Phys Fitness 46(1):57-61. 